\title{
Switching of an Azobenzene-Tripod Molecule on $\mathrm{Ag}(111)$
}

\author{
Katharina Scheil, ${ }^{\dagger}$ Thiruvancheril G. Gopakumar, ${ }^{\ddagger}$ Julia Bahrenburg, ${ }^{\S}$ Friedrich Temps, ${ }^{\S}$ \\ Reinhard Johann Maurer," Karsten Reuter," and Richard Berndt* ${ }^{\dagger}$ \\ ${ }^{\dagger}$ Institut für Experimentelle und Angewandte Physik, Christian-Albrechts-Universität, 24098 Kiel, Germany \\ ${ }^{\ddagger}$ Department of Chemistry, Indian Institute of Technology Kanpur, Kanpur 208016, India \\ ${ }^{\S}$ Institut für Physikalische Chemie, Christian-Albrechts-Universität, 24098 Kiel, Germany \\ "Lehrstuhl für Theoretische Chemie, Technische Unversität München, 85747 Garching, Germany
}

Supporting Information

ABSTRACT: The trans-cis isomerization makes azobenzene $(\mathrm{AB})$ a robust molecular switch. Once adsorbed to a metal, however, the switching is inefficient or absent due to rapid excited-state quenching or loss of the trans-cis bistability. We find that tris-[4(phenylazo)-phenyl]-amine is a rather efficient switch on $\operatorname{Ag}(111)$. Using scanning tunneling and atomic force microscopy at submolecular resolution along with density functional theory calculations, we show that the switching process is no trans-cis isomerization but rather a reorientation of the $\mathrm{N}-\mathrm{N}$ bond of an $\mathrm{AB}$ unit. It proceeds through a twisting motion of the azo-bridge that leads to a lateral shift of a phenyl ring. Thus, the role of the Ag substrate is ambivalent. While it suppresses the original bistability of the azobenzene units, it creates a new one by inducing a barrier for the rotation of the $\mathrm{N}-\mathrm{N}$ bond.

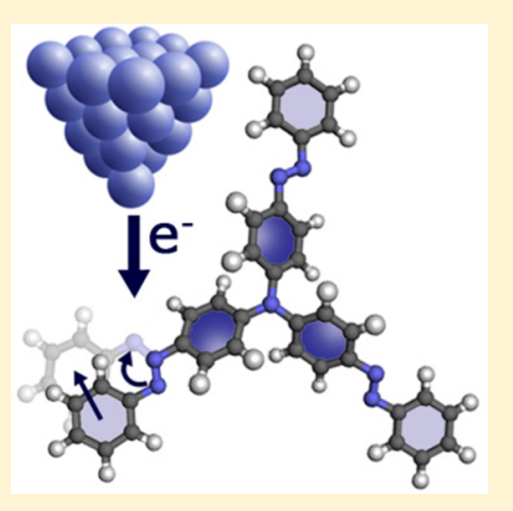

$\mathrm{T}$ he trans-cis isomerization of azobenzene $(\mathrm{AB})$ and its derivatives has been investigated in detail, partially because $A B$ may be modified with various substituents and still exhibits robust light-driven switching. ${ }^{1,2}$ Unfortunately, this robustness does not extend to the adsorption on metal substrates. Drastically reduced efficiencies of light-induced switching of $\mathrm{AB}$ when adsorbed to Au have been reported and attributed to rapid excited-state quenching. ${ }^{3-8}$ Dispersioncorrected density functional theory (DFT) calculations have recently identified an additional factor that may be involved in reducing efficiency. ${ }^{9}$ Once adsorbed on $\mathrm{Au}(111)$ or $\mathrm{Ag}(111)$, the barrier that prevents the cis isomer to return to the trans ground state via a rotation is drastically reduced. This effect, which may effectively eliminate trans-cis bistability, was predicted to be particularly significant on $\operatorname{Ag}(111)$ and more reactive substrates. An increase in the rate of thermal cis-trans isomerization of azobenzene-containing molecules has been reported from gold nanoparticles. ${ }^{10,11}$

Using a scanning tunneling microscope (STM), extreme current densities may be achieved through a single molecule. ${ }^{12-15}$ Using this approach, electron-induced switching of $\mathrm{AB}$ derivatives on $\mathrm{Au}$ remains possible, although efficiencies scatter widely. ${ }^{8,16-20}$ Despite expectations for azobenzene (AB)-containing molecules on $\operatorname{Ag}(111),{ }^{9}$ we find that switching of tris-[4-(phenylazo)-phenyl]-amine (TPAPA) on $\operatorname{Ag}(111)$ is feasible.

TPAPA comprises three $\mathrm{AB}$ units connected via an amino linker in a 3-fold symmetric fashion. ${ }^{21-23} \mathrm{We}$ demonstrate that each of the $A B$ subunits may be reversibly and selectively switched between two states by injecting electrons. Switching may also be triggered by passing current through the central amino nitrogen atom. From scanning tunneling spectroscopy and atomic force microscopy (AFM) along with extensive density functional theory (DFT) calculations, we find that the switching is not due to a trans-cis isomerization. Rather, it involves a reorientation of the $\mathrm{N}-\mathrm{N}$ bond of $\mathrm{AB}$, which we suggest to proceed through a twisting motion of the azo-bridge that leads to a shift of a phenyl ring. The $A B$ subunit is transformed between two chiral configurations that are distinct and metastable on the $\operatorname{Ag}(111)$ surface.

Beyond double-bond isomerization a variety of electroninduced reactions have been observed from adsorbed molecules, which encompass ring closing/opening, ${ }^{24}$ charge transfer, ${ }^{25,26}$ conformational isomerization, ${ }^{27-30}$ changes of spin-state, ${ }^{31,32}$ and ligand transfer. ${ }^{33}$ Recent reviews may be found in refs 34-36.

The $\operatorname{Ag}(111)$ substrate and etched $\mathrm{W}$ tips were cleaned by $\mathrm{Ar}^{+}$sputtering and annealing. The tips were further coated with silver by indenting them into the substrate. TPAPA molecules in a Ta crucible were repeatedly degassed before sublimating them at $\sim 150{ }^{\circ} \mathrm{C}$ onto clean $\operatorname{Ag}(111)$ surfaces kept at ambient temperature in ultra high vacuum (UHV). The experiments were then performed with a STM and an AFM/STM operated in $\mathrm{UHV}$ at $\sim 5 \mathrm{~K}$. Differential conductance $(\mathrm{d} I / \mathrm{d} V)$ spectra

Received: May 11, 2016

Accepted: May 19, 2016 
were measured with a lock-in amplifier by superimposing a modulation $\left(5-10 \mathrm{mV}_{\mathrm{rms}}, 7 \mathrm{kHz}\right)$ onto the sample voltage $V$.

Figure 1a shows the structure of TPAPA on $\operatorname{Ag}(111)$, as predicted using dispersion-corrected DFT calculations (PBE

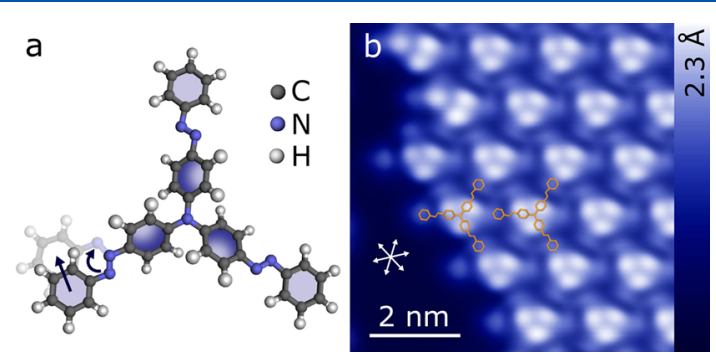

Figure 1. (a) Top view of the minimum energy structure of TPAPA on $\operatorname{Ag}(111)$ from DFT calculations (substrate not shown, extended models displayed in the Supporting Information). Light and dark blue indicate the outer and inner phenyl rings, respectively. The shading of the inner rings shows their $\sim 30^{\circ}$ anticlockwise out-of-plane twist. The outer phenyl groups are located on the left-hand side of the plane defined by the azobenzene $(A B)$ molecular axis and the surface normal. This handedness of the adsorbed $\mathrm{AB}$ subunits is denoted $\mathrm{S}$. Switching of an $\mathrm{AB}$ subunit leads to modified structure (gray). It involves a lateral shift (arrow) of the outer phenyl ring and a twirling motion of the $\mathrm{N}-\mathrm{N}$ bond (curved arrow). (b) STM topograph (1.0 V, $100 \mathrm{pA}$ ) of an island of TPAPA molecules on $\mathrm{Ag}(111)$. Scaled models are overlaid. Double-headed arrows indicate the compact directions of the $\operatorname{Ag}(111)$ surface.

+ vdW $^{\text {surf37,38 }}$ using the CASTEP ${ }^{39}$ package). We denote the phenyl groups connected via the amino nitrogen as inner (dark blue in Figure 1a) and the other ones as outer groups (light blue). Steric repulsion between the hydrogen atoms of the inner phenyls induces a propeller-like twist of the $\mathrm{AB}$ ligands from the molecular plane of $\sim 40^{\circ}$ in gas phase and $\sim 30^{\circ}$ on $\operatorname{Ag}(111) \cdot{ }^{22,23}$ Viewed from the center of an adsorbed molecule, the twist may be clockwise or anticlockwise, leading to a chirality of the molecule. The energetically most favorable configuration is thereby an all-trans form, with the outer phenyl rings lying flat on the surface to maximize dispersion interaction (for more details, see the Supporting Information).

An STM topograph of a part of a TPAPA island on $\operatorname{Ag}(111)$ is shown in Figure 1b. Each molecule exhibits three main protrusions ( $\sim 220 \mathrm{pm}$ apparent height with respect to the $\mathrm{Ag}$ substrate) near its center, which we attribute to the inner phenyl rings. Models are overlaid over some molecules to show their orientations, which are similar to TPAPA on $\mathrm{Au}(111){ }^{23}$ In the interior of the island it is a priori not clear which set of protrusions belongs to a given molecule. The molecules at island edges, however, provide a clear indication of the position of the outer phenyl rings. The outer phenyls lead to three lower protrusions of $\sim 170 \mathrm{pm}$ apparent height. The height at the approximate positions of the azo groups between the phenyl rings is lower by $\sim 20 \mathrm{pm}$. This distinct depression at the position of the $\mathrm{N}-\mathrm{N}$ azo-bridge is in qualitative agreement with previous STM data from $\mathrm{AB}$ on metal substrates. $3,8,17,23,27,40$ The average intermolecular distance extracted from STM images is $(1.7 \pm 0.2) \mathrm{nm}$, and the molecular lattice is rotated by $(8 \pm 2)^{\circ}$ with respect to the compact directions of $\operatorname{Ag}(111)$. We note in passing that most islands observed were almost enantiopure.

Next, switching of TPAPA in islands was investigated. Placing the tip over an azo bridge (dot in Figure 2a) and increasing the sample voltage beyond $\sim 1.1 \mathrm{~V}$ leads to a clear change of the addressed $A B$ subunit, as shown in Figure $2 b$. Currents of $\sim 1.1 \mathrm{nA}$ were used to obtain a convenient rate of switching events. By successively repeating this procedure all three $A B$ units were switched (Figure $2 c, d$ ). To highlight the changes in the topographs, Figure $2 \mathrm{e}-\mathrm{g}$ displays difference images. They reveal little change at the molecular center and the inner phenyl rings but a drastic modification of the area of the azo bridges. Subsequently, the changes were reversed (Figure $2 \mathrm{~h}-\mathrm{m}$ ).

Topographic changes of the outer phenyl rings are most obvious at island edges. Figure 3 shows $(\mathrm{a}, \mathrm{b})$ models of molecules at an island edge $(\mathrm{c}, \mathrm{d})$ before and $(\mathrm{e}, \mathrm{f})$ after

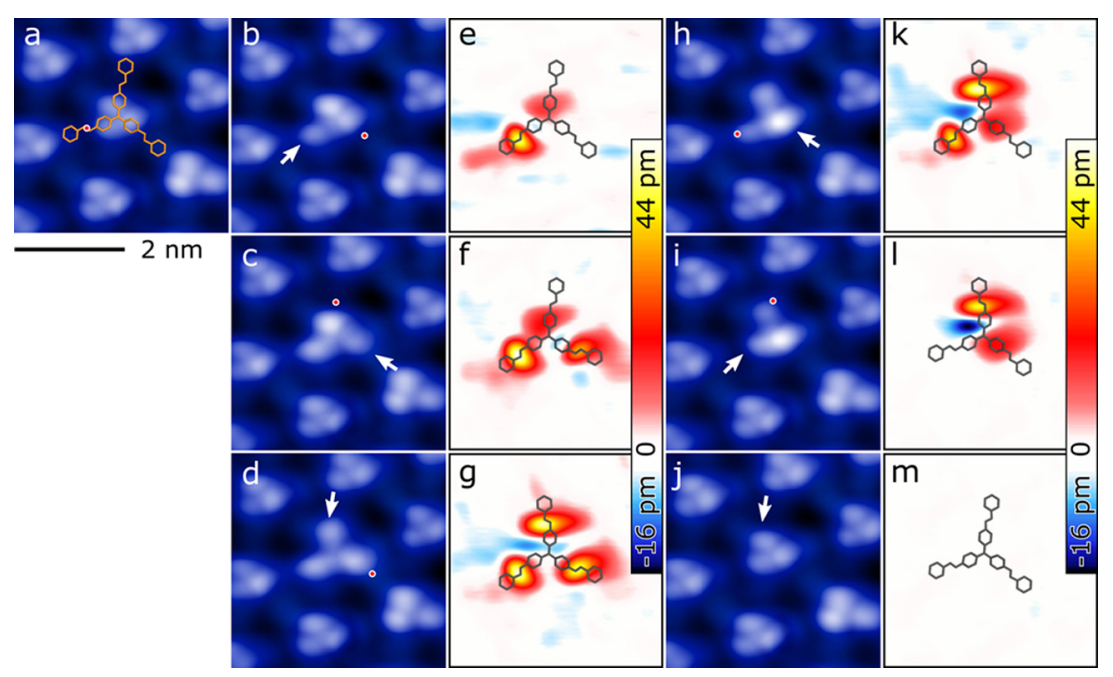

Figure 2. $(\mathrm{a}-\mathrm{d}, \mathrm{h}-\mathrm{j})$ Constant current topographs $(1.0 \mathrm{~V}, 100 \mathrm{pA})$ from a TPAPA island. Dots indicates points of current injection for switching $(V$ $=1.3 \mathrm{~V}, I=1.1 \mathrm{nA}$ ). Arrows indicate switched $\mathrm{AB}$ subunits. (a) Initially the molecule at the center is in an all-trans state. (b) New state induced by passing current through the azo bridge of the $A B$ subunit on the lower left. (c, d) New states obtained through current-induced of the remaining $A B$ subunits. $(h-j)$ Stepwise reversal of the switching until the original state is reached. $(e-g, k-m)$ Difference images obtained by subtracting image $(a)$ from $(b-d)$ and $(h-j)$. Scaled models of the molecule in panel a are overlaid. The largest changes in the images are localized to the positions of the azo bridges. 


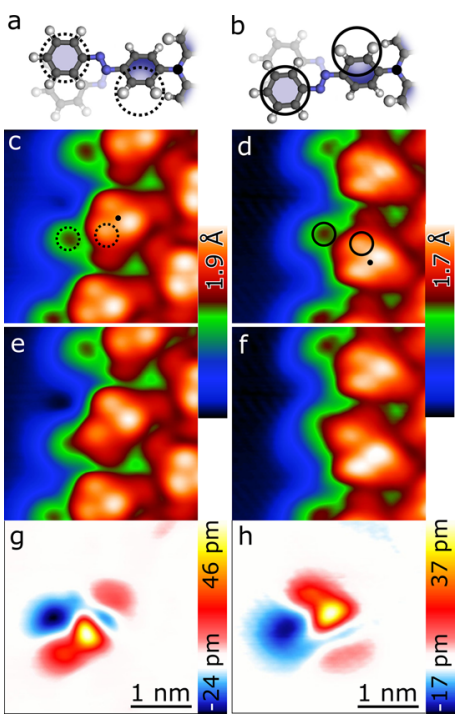

Figure 3. Switching of molecules at the edges of two islands with different molecular chiralities. Viewed from the center of a molecule, the inner phenyl rings are twisted by $\sim 30^{\circ}$ (a) clockwise and (b) anticlockwise. (a,b) Models show trans-configurations of one $\mathrm{AB}$ unit. Circles indicate the positions of protrusions observed in constant current topographs. Dots mark the $\mathrm{N}$ center of molecules. $(\mathrm{c}, \mathrm{d})$ Topographs $(V=1.0 \mathrm{~V}, I=100 \mathrm{pA})$ of TPAPA at island edges corresponding to the models in panels a and b. (e, f) Topographs obtained after switching of the $A B$ units at the island rim. (g,h) Difference images $e-c$ and $f-d$.

switching. The corresponding changes are displayed in Figures $3 \mathrm{~g}$,h. The data confirm the apparent height change at the azo bridge and also reveal a lateral motion of the maximum due to the outer phenyl ring by $\sim 1.5 \AA$. Within islands, the phenyl rings are surrounded by the tallest features of neighboring molecules. This renders a quantitative determination of the lateral shift from constant-current images more difficult. At first glance, the shift actually appears to be smaller; however, when the superposition of the currents to the relevant phenyl ring and the neighbor is taken into account, a consistent shift is found (see the Supporting Information).

Switching may also be induced by passing current through the center of a TPAPA molecule. Time series of the current (Figure 4) reveal abrupt current fluctuations between four levels, which (in a sequence of increasing currents) correspond

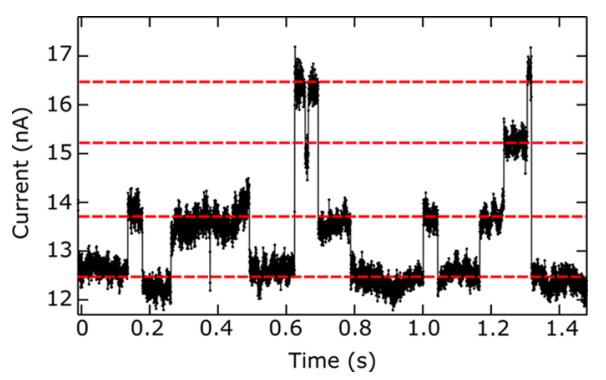

Figure 4. After placing the tip over the center of a TPAPA molecule, the current feedback was disabled and time series of the current were measured at selected sample voltages. Abrupt current fluctuations occurred. The example shown was recorded at $V=1.5 \mathrm{~V}$ and reveals four distinct current levels indicated by dashed lines. The lowest level is observed on all-trans TPAPA. Increasing levels reflect 1, 2, and 3 switched azobenzene subunits. to the pristine molecule and the states with 1,2 , or 3 switched $\mathrm{AB}$ units. The data demonstrate that the switching is reversible; however, because current is injected at the center of the TPAPA molecule, there is no preference for a specific $A B$ subunit. Selectivity for a specific $A B$ subunit is achieved by injection into a $\mathrm{N}-\mathrm{N}$ bond, as demonstrated in Figure 2.

Switching occurs at both bias polarities with yields varying from $Y \approx 10^{-13}$ (at $V=0.8$ and $-1.8 \mathrm{~V}$ ) to $Y \approx 10^{-11}$ at elevated currents and voltages (see SI for details). At positive sample voltage, the switching rate approximately follows a power law $\approx$ $I^{2}$, which may indicate a two-electron process.

The most obvious switching process to consider for $A B$ and its derivatives is trans-cis isomerization; however, we exclude this possibility in the present case for two reasons. First, transcis isomerization significantly modifies the electronic states of $\mathrm{AB}$ in the gas phase and also on surfaces. ${ }^{3,8,27,40,41} \mathrm{~d} I / \mathrm{d} V$ spectra of pristine and switched TPAPA measured at characteristic positions (Figure 5), however, reveal merely

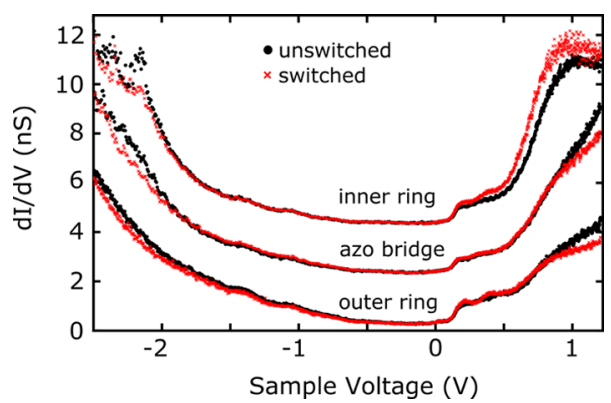

Figure 5. Differential conductance $(\mathrm{d} I / \mathrm{d} V)$ spectra acquired above the inner and outer phenyl rings and the azo bridge of an $A B$ subunit of TPAPA. Data were recorded from a pristine all-trans molecules and a switched isomer. Current feedback was opened at $V=-0.1 \mathrm{~V}$ and $I=$ $500 \mathrm{pA}$. The spectra are vertically offset by 0,2 , and $4 \mathrm{nS}$ for clarity. The data indicate positive and negative ion resonances that vary little between the isomers.

minor differences between the switched and pristine states. Second, our DFT calculations revealed a number of stable cis states (three shown in the SI, Figure S6), all of which involve significant geometrical and electronic changes compared with the trans state. As detailed later, none of these changes are consistent with our experimental data, which suggests a much more subtle structural and electronic change upon switching.

Figure 6a shows a constant-current STM image of molecules with varying numbers of switched $A B$ subunits. Because constant-current STM images may be affected by electronic effects, we performed additional measurements combining STM and noncontact AFM at submolecular resolution. Figure 6b,c displays AFM frequency shift data and a current map measured at constant tip height above the substrate. In the stable cis conformations identified via DFT (see SI), the outer phenyl rings are either strongly laterally displaced or switched to a tilted or almost vertical arrangement on the surface. These geometries are incompatible with the low contrast of the outer phenyl rings in the AFM data of Figure $6 \mathrm{~b}$. Rather, these data indicate that the inner rings protrude farthest from the surface, whereas the outer ones appear to lie rather flat. On the basis of the current map of Figure $6 c$, where the outer rings, the inner rings, and the central amino linker form a straight line, this scenario can be excluded. 


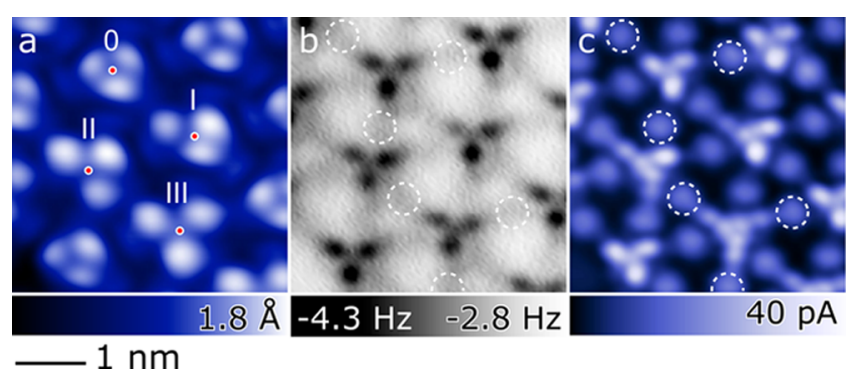

Figure 6. (a) Constant-current topograph (1 V, $100 \mathrm{pA})$. Molecules labeled $\mathbf{0}$ to III exhibit zero, one, two, and three switched $A B$ subunits. (b) AFM frequency shift data from the same area measured at constant tip height. (Amplitude of cantilever oscillation 1 A.) The positions of the outer rings are marked with dashed circles. While a significant frequency shift is found above inner phenyl rings the outer rings and the azo bridge cause hardly any contrast. (c) Current map recorded at constant tip height from the same area.

Another possible switching mechanism is a lateral shift of an outer phenyl ring. The outer phenyl rings can be situated either to the left or to the right of the plane defined by the azobenzene molecular axis and the surface normal. This reflects a handedness (denoted $\mathrm{S}$ and $\mathrm{R}$, respectively) of the adsorbed $\mathrm{AB}$ subunits. DFT calculations yield metastable surface geometries for $\mathrm{R}$ and $\mathrm{S}$ conformers of an $\mathrm{AB}$ subunit of TPAPA. When the inner phenyl rings are twisted anticlockwise, the $S$ configuration is minimally more stable. This higher stability is associated with a change in height of almost $0.6 \AA$ of the $\mathrm{N}$ atom in the azo-bridge, which is bound to the inner phenyl ring. The corresponding isomerization reaction requires a torsional motion of the nitrogen atoms in the azo-bridge. We propose that this rearrangement involves a twisting motion of the central nitrogen atoms around each other coupled to a lateral shift of the outer phenyl ring rather than a rotation that lifts the outer phenyl ring out of the surface plane. The calculated energy barrier height for this process is $0.47 \mathrm{eV}$. This value is consistent with the experiments where significant switching rates were observed at bias voltages of $0.8 \mathrm{~V}$ and above.

An out-of-plane rotation of a single phenyl ring has been reported from 3,3'-dicyanobenzene (dimeta-cyanobenzene, $\mathrm{DMC})$ on $\mathrm{Au}(111) .^{27} \mathrm{We}$ do not favor this mechanism in the present case of TPAPA on $\operatorname{Ag}(111)$. According to our DFT $+\mathrm{vdW}$ surf calculations it exhibits a significantly higher barrier due to the additional energy penalty of losing the dispersion interactions between phenyl ring and surface.

The localized change in apparent height and tunneling conductance as observed in the STM can therefore be understood as a conformational switching from an $S$ to an $R$ state and a corresponding uplifting of the central azo-bridge at almost minimal lateral displacement of the phenyl groups. Much in accordance with the measured $\mathrm{d} I / \mathrm{d} V$ curves, this conformational switching occurs with minimal modification of the energetic position of the molecular orbitals with respect to the Fermi level.

In summary, the three azobenzene units of the compound TPAPA on $\operatorname{Ag}(111)$ may each reversibly be switched between two distinct states. Switching is triggered by passing current through the center of a molecule or, to achieve selectivity, through the azo bridges. The efficiency of the process is comparable to molecular switching of $\mathrm{AB}$ derivatives that were decoupled from a Au substrate by spacer groups; ${ }^{3,18,40}$ however, the switching does not involve the trans and cis isomers of $\mathrm{AB}$ that were predicted to lack of bistability on $\operatorname{Ag}(111)$. It rather involves a lateral motion of a phenyl ring and a twisting motion of the azo bridges. Thus, the role of the $\mathrm{Ag}$ substrate is ambivalent. While it suppresses the original bistability of azobenzene it creates a new switching function that is based on surface-induced chirality.

\section{ASSOCIATED CONTENT}

\section{Supporting Information}

The Supporting Information is available free of charge on the ACS Publications website at DOI: 10.1021/acs.jpclett.6b01011.

SI-1: Current dependency of switching rate. SI-2: Lateral shift of phenyl within islands. SI-3: Details of dispersioncorrected density functional theory calculations. (PDF)

\section{AUTHOR INFORMATION}

\section{Corresponding Author}

*E-mail: berndt@physik.uni-kiel.de.

Notes

The authors declare no competing financial interest.

\section{ACKNOWLEDGMENTS}

Funding by the Deutsche Forschungsgemeinschaft through SFB 677 (K.S., T.G.G., J.B., F.T., and R.B.) and RE1509/16-2 (R.J.M. and K.R.) is acknowledged. Computing resources were provided by the Leibniz Supercomputing Center (LRZ), grant no. pr94sa. The authors furthermore thank Tugba DavranCandan for support with initial electronic structure calculations. R.J.M. is grateful for discussions with Alessandro de Vita.

\section{REFERENCES}

(1) Rau, H. In Photochemistry and Photophysics; Rabek, J. F., Scott, G. W., Eds.; CRC Press: Boca Raton, FL, 1989; pp 119-121; Vol. 2.

(2) Schultz, T.; Quenneville, J.; Levine, B.; Toniolo, A.; Martínez, T. J.; Lochbrunner, S.; Schmitt, M.; Shaffer, J. P.; Zgierski, M. Z.; Stolow, A. Mechanism and Dynamics of Azobenzene Photoisomerization. J. Am. Chem. Soc. 2003, 125, 8098-9.

(3) Comstock, M. J.; Levy, N.; Kirakosian, A.; Cho, J.; Lauterwasser, F.; Harvey, J. H.; Strubbe, D. A.; Fréchet, J. M. J.; Trauner, D.; Louie, S. G.; et al. Reversible Photomechanical Switching of Individual Engineered Molecules at a Metallic Surface. Phys. Rev. Lett. 2007, 99, 038301.

(4) Hagen, S.; Leyssner, F.; Nandi, D.; Wolf, M.; Tegeder, P. Reversible Switching of Tetra-Tert-Butyl-Azobenzene on a $\mathrm{Au}(111)$ Surface induced by Light and Thermal Activation. Chem. Phys. Lett. 2007, 444, 85-90.

(5) McNellis, E. R.; Bronner, C.; Meyer, J.; Weinelt, M.; Tegeder, P.; Reuter, K. Azobenzene versus Tetra-Tert-Butyl-Azobenzene (TBA) at $\mathrm{Au}(111)$ : Characterizing the Role of Spacer Groups. Phys. Chem. Chem. Phys. 2010, 12, 6404-6412.

(6) Cho, J.; Berbil-Bautista, L.; Levy, N.; Poulsen, D.; Fréchet, J. M. J.; Crommie, M. F. Functionalization, Self-Assembly, and Photoswitching Quenching for Azobenzene Derivatives adsorbed on $\mathrm{Au}(111)$. J. Chem. Phys. 2010, 133, 234707.

(7) Henzl, J.; Puschnig, P.; Ambrosch-Draxl, C.; Schaate, A.; Ufer, B.; Behrens, P.; Morgenstern, K. Photoisomerization for a Molecular Switch in Contact with a Surface. Phys. Rev. B: Condens. Matter Mater. Phys. 2012, 85, 035410.

(8) Choi, B.; Kahng, S.; Kim, S.; Kim, H.; Kim, H. W.; Song, Y. J.; Ihm, J.; Kuk, Y. Conformational Molecular Switch of the Azobenzene Molecule: A Scanning Tunneling Microscopy Study. Phys. Rev. Lett. 2006, 96, 156106. 
(9) Maurer, R. J.; Reuter, K. Bistability Loss as a Key Feature in Azobenzene (Non-) Switching on Metal Surfaces. Angew. Chem. 2012, 124, 12175-12177.

(10) Hallett-Tapley, G. L.; D’Alfonso, C.; Pacioni, N. L.; McTiernan, C. D.; González-Béjar, M.; Lanzalunga, O.; Alarcon, E. I.; Scaiano, J. C. Gold Nanoparticle Catalysis of the Cis-Trans Isomerization of Azobenzene. Chem. Commun. 2013, 49, 10073-10075.

(11) Titov, E.; Lysyakova, L.; Lomadze, N.; Kabashin, A. V.; Saalfrank, P.; Santer, S. Thermal Cis-to-Trans Isomerization of Azobenzene-Containing Molecules Enhanced by Gold Nanoparticles: An Experimental and Theoretical Study. J. Phys. Chem. C 2015, 119, 17369-17377.

(12) Néel, N.; Kröger, J.; Limot, L.; Frederiksen, T.; Brandbyge, M.; Berndt, R. Controlled Contact to a $\mathrm{C}_{60}$ Molecule. Phys. Rev. Lett. 2007, 98, 065502.

(13) Schull, G.; Frederiksen, T.; Brandbyge, M.; Berndt, R. Passing Current through Touching Molecules. Phys. Rev. Lett. 2009, 103, 206803.

(14) van der Molen, S. J.; Liljeroth, P. Charge Transport through Molecular Switches. J. Phys.: Condens. Matter 2010, 22, 133001.

(15) Vazquez, H.; Skouta, R.; Schneebeli, S.; Kamenetska, M.; Breslow, R.; Venkataraman, L.; Hybertsen, M. S. Probing the Conductance Superposition Law in Single-Molecule Circuits with Parallel Paths. Nat. Nanotechnol. 2012, 7, 663-667.

(16) A detailed comparison of data from different derivatives is difficult because varying bias voltages and currents have been used. For instance, for $\mathrm{AB}$ on $\mathrm{Au}(111)$ a switching yield per electron $Y \approx 10^{-18}$ at $-1.5 \mathrm{~V}$ and $0.5 \mathrm{nA}$ was reported, ${ }^{8}$ for anilino-nitro $\mathrm{AB}$ on $\mathrm{Au}(111)$ $Y \approx 10^{-9}$ at $2.5 \mathrm{~V}$ and $0.5 \mathrm{nA},{ }^{19}$ for 4-(4-nitrophenylazo)aniline on $\mathrm{Au}(111) Y \approx 10^{-8}$ at $0.7 \mathrm{~V},{ }^{17}$ for trans-cis isomerisation of dihydroxy$\mathrm{AB}$ adsorbed on $\mathrm{NaCl}$ the yield is $Y \approx 10^{-8}$ at $0.7 \mathrm{~V},{ }^{20}$ and for tetratert-butyl $\mathrm{AB}$ on $\mathrm{Au}(111) Y \approx 10^{-8}$ at $1.6 \mathrm{~V}, 0.5 \mathrm{nA}$, increasing to $Y \approx$ $10^{-7}$ at $1.6 \mathrm{~V}, 2 \mathrm{nA}^{18}$

(17) Henzl, J.; Mehlhorn, M.; Gawronski, H.; Rieder, K.-H.; Morgenstern, K. Reversible Cis-Trans Isomerization of a Single Azobenzene Molecule. Angew. Chem., Int. Ed. 2006, 45, 603-606.

(18) Alemani, M.; Selvanathan, S.; Ample, F.; Peters, M. V.; Rieder, K.-H.; Moresco, F.; Joachim, C.; Hecht, S.; Grill, L. Adsorption and Switching Properties of Azobenzene Derivatives on Different Noble Metal Surfaces: $\mathrm{Au}(111), \mathrm{Cu}(111)$, and $\mathrm{Au}(100)$. J. Phys. Chem. C 2008, 112, 10509-10514.

(19) Henzl, J.; Morgenstern, K. An Electron induced TwoDimensional Switch made of Azobenzene Derivatives Anchored in Supramolecular Assemblies. Phys. Chem. Chem. Phys. 2010, 12, 60356044.

(20) Safiei, A.; Henzl, J.; Morgenstern, K. Isomerization of an Azobenzene Derivative on a Thin Insulating Layer by Inelastically Tunneling Electrons. Phys. Rev. Lett. 2010, 104, 216102.

(21) Takahashi, T.; Tanino, T.; Ando, H.; Nakano, H.; Shirota, Y. Surface Relief Grating Formation using a Novel Azobenzene-Based Photochromic Amorphous Molecular Material, Tris[4-(Phenylazo)Phenyl]Amine. Mol. Cryst. Liq. Cryst. 2005, 430, 9-14.

(22) Bahrenburg, J.; Sievers, C. M.; Schönborn, J. B.; Hartke, B.; Renth, F.; Temps, F.; Näther, C.; Sönnichsen, F. D. Photochemical Properties of Multi-Azobenzene Compounds. Photochem. Photobiol. Sci. 2013, 12, 511-518.

(23) Gopakumar, T. G.; Davran-Candan, T.; Bahrenburg, J.; Maurer, R. J.; Temps, F.; Reuter, K.; Berndt, R. Broken Symmetry of an Adsorbed Molecular Switch Determined by Scanning Tunneling Spectroscopy. Angew. Chem., Int. Ed. 2013, 52, 11007-11010.

(24) Bronner, C.; Schulze, G.; Franke, K. J.; Pascual, J. I.; Tegeder, P. Switching Ability of Nitro-Spiropyran on $\mathrm{Au}(111)$ : Electronic Structure Changes as a Sensitive Probe during a Ring-Opening Reaction. J. Phys.: Condens. Matter 2011, 23, 484005.

(25) Jäckel, F.; Perera, U. G. E.; Iancu, V.; Braun, K.-F.; Koch, N.; Rabe, J. P.; Hla, S.-W. Investigating Molecular Charge Transfer Complexes with a Low Temperature Scanning Tunneling Microscope. Phys. Rev. Lett. 2008, 100, 126102.
(26) Karan, S.; Li, N.; Zhang, Y.; He, Y.; Hong, I.-P.; Song, H.; Lü, J.T.; Wang, Y.; Peng, L.; et al. Spin Manipulation by Creation of SingleMolecule Radical Cations. Phys. Rev. Lett. 2016, 116, 027201.

(27) Henningsen, N.; Rurali, R.; Franke, K. J.; Fernández-Torrente, I.; Pascual, J. I. Trans to Cis Isomerization of an Azobenzene Derivative on a $\mathrm{Cu}(100)$ Surface. Appl. Phys. A: Mater. Sci. Process. 2008, 93, 241-246.

(28) Wang, Y.; Kröger, J.; Berndt, R.; Hofer, W. A. Pushing and Pulling a Sn Ion through an Adsorbed Phthalocyanine Molecule. J. Am. Chem. Soc. 2009, 131, 3639-3643.

(29) Wang, Y. F.; Ge, X.; Schull, G.; Berndt, R.; Tang, H.; Bornholdt, C.; Koehler, F.; Herges, R. Switching Single Azopyridine Supramolecules in Ordered Arrays on $\mathrm{Au}(111)$. J. Am. Chem. Soc. 2010, 132, 1196-1197.

(30) Perera, U. G. E.; Ample, F.; Kersell, H.; Zhang, Y.; Vives, G.; Echeverria, J.; Grisolia, M.; Rapenne, G.; Joachim, C.; Hla, S.-W. Controlled Clockwise and Anticlockwise Rotational Switching of a Molecular Motor. Nat. Nanotechnol. 2012, 8, 46-51.

(31) Gopakumar, T. G.; Matino, F.; Naggert, H.; Bannwarth, A.; Tuczek, F.; Berndt, R. Electron-Induced Spin Crossover of Single Molecules in a Bilayer on Gold. Angew. Chem., Int. Ed. 2012, 51, $6262-6266$.

(32) Miyamachi, T.; Gruber, M.; Davesne, V.; Bowen, M.; Boukari, S.; Joly, L.; Scheurer, F.; Rogez, G.; Yamada, T. K.; Ohresser, P.; et al. Robust Spin Crossover and Memristance Across a Single Molecule. Nat. Commun. 2012, 3, 938.

(33) Gopakumar, T. G.; Tang, H.; Morillo, J.; Berndt, R. Transfer of $\mathrm{Cl}$ Ligands between Adsorbed Iron Tetraphenylporphyrin Molecules. J. Am. Chem. Soc. 2012, 134, 11844-11847.

(34) Weinelt, M.; von Oppen, F. Molecular Switches at Surfaces. J. Phys.: Condens. Matter 2012, 24, 390201.

(35) Pathem, B. K.; Claridge, S. A.; Zheng, Y. B.; Weiss, P. S. Molecular Switches and Motors on Surfaces. Annu. Rev. Phys. Chem. 2013, 64, 605-630.

(36) Zhang, J. L.; Zhong, J. Q.; Lin, J. D.; Hu, W. P.; Wu, K.; Xu, G. Q.; Wee, A. T. S.; Chen, W. Towards Single Molecule Switches. Chem. Soc. Rev. 2015, 44, 2998-3022.

(37) Perdew, J. P.; Burke, K.; Ernzerhof, M. Generalized Gradient Approximation Made Simple. Phys. Rev. Lett. 1996, 77, 3865-3868.

(38) Ruiz, V.; Liu, W.; Zojer, E.; Scheffler, M.; Tkatchenko, A. Density-Functional Theory with Screened van der Waals Interactions for the Modeling of Hybrid Inorganic-Organic Systems. Phys. Rev. Lett. 2012, 108, 146103 .

(39) Clark, S.; Segall, M.; Pickard, C.; Hasnip, P.; Probert, M.; Refson, K.; Payne, M. First Principles Methods using CASTEP. Z. Kristallogr. - Cryst. Mater. 2005, 220, 567-570.

(40) Alemani, M.; Peters, M. V.; Hecht, S.; Rieder, K.-H.; Moresco, F.; Grill, L. Electric Field-Induced Isomerization of Azobenzene by STM. J. Am. Chem. Soc. 2006, 128, 14446-14447.

(41) McNellis, E.; Meyer, J.; Baghi, A. D.; Reuter, K. Stabilizing a Molecular Switch at Solid Surfaces: A Density Functional Theory Study of Azobenzene on $\mathrm{Cu}(111), \mathrm{Ag}(111)$, and $\mathrm{Au}(111)$. Phys. Rev. B: Condens. Matter Mater. Phys. 2009, 80, 035414. 